\title{
Cytotoxicity of Neisseria gonorrhoeae for Human Peripheral Blood Phagocytes
}

\author{
By S. G. CASEY, D. R. VEALE* AND H. SMITH \\ Department of Microbiology, University of Birmingham, P.O. Box 363, \\ Birmingham B15 2TT, U.K.
}

(Received 12 August 1982)

\begin{abstract}
The toxicity of gonococci [strain BS4 (agar)] for human peripheral blood polymorphonuclear phagocytes, infected in vitro, was assessed by light microscopic examination of Giemsa stained cell deposits of polymorphonuclear phagocytes which had ingested these bacteria. The cytotoxicity elicited by viable gonococci, assessed by percentage lysis and concomitant reduction in the number of polymorphonuclear phagocytes increased as the ratio of gonococci to phagocytes in the original suspension mixture was raised. Pretreatment of viable gonococci with antiserum raised to whole organisms increased the cytotoxic effect produced by the organisms. Killed (heat or UV irradiation) gonococci caused little or no cytotoxicity, even when the organisms were pretreated with specific antiserum. Hence, the lysis of polymorphonuclear phagocytes appears to be caused by a factor or factors produced by viable gonococci and not by LPS per se.
\end{abstract}

\section{INTRODUCTION}

Acute gonococcal urethritis in the male is characterized by a profuse purulent discharge from the urethra. The majority of cells in the exudate are polymorphonuclear (PMN) phagocytes, of which a small proportion contain large numbers of intracellular gonococci (Ovcinnikov \& Delectorskij, 1971; Veale et al., 1979). Experiments in vitro have shown that gonococci can survive and multiply in human PMN phagocytes (Veale et al., 1979; Casey et al., 1979, 1980) and there is also evidence that they can be toxic for phagocytes.

Veale et al. (1979) found that, at high ratios of gonococci to PMN phagocytes in a phagocytosis test in vitro, phagocytic cells disintegrated after ingesting large numbers of gonococci. Novotny et al. (1977) described the presence, in urethral exudate, of clumps of apparently intact gonococci surrounded by the debris of phagocytic cells. These observations support the earlier view of Scherp (1955) that intracellular gonococci can destroy phagocytes. Changes in the shape (Gibbs \& Roberts, 1975) and attachment (Veale et al., 1976) of phagocytes observed at low ratios of gonococci to phagocytes could also relate to a cytotoxic process.

Toxic components isolated from gonococci include the LPS endotoxin (Peacock \& Schmale, 1969) and a cytoplasmic polymer (Cheng et al., 1974) both of which damaged chick embryos. Whole gonococci and gonococcal LPS caused decreased mucociliary wave frequency and produced cell damage in human fallopian tube organ cultures (Mårdh et al., 1979; Gregg et al., 1981; McGee et al., 1981; Melly et al., 1981). Gonococcal phospholipase A (Senff et al., 1976) is another possible toxic agent (Novotny et al., 1977).

In the present study, the ability of gonococci to lyse PMN phagocytes has been re-assessed and the effects of heat, UV irradiation and specific antiserum on the toxicity have been investigated. 


\section{METHODS}

Neisseria gonorrhoeae. Strain BS4 (agar) was derived, stored and cultured as described previously (Penn et al., 1976, 1977a, b).

Pretreatment of gonococci. Gonococcal suspensions were prepared as described previously (Witt et al., 1976) with the exception that Trypticase Soy Broth (BBL) was supplemented with $10 \%(\mathrm{v} / \mathrm{v})$ heated $\left(56^{\circ} \mathrm{C}, 30 \mathrm{~min}\right)$ newborn calf serum (Flow Laboratories) and clumps were dispersed by vortex mixing (vortex mixer; Hook and Tucker Ltd,

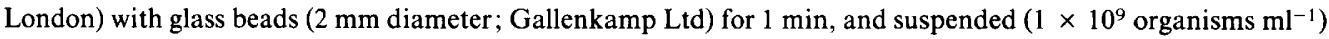
in Parker medium 199 (Wellcome) supplemented with $10 \%(\mathrm{v} / \mathrm{v})$ homologous, heated $\left(56^{\circ} \mathrm{C}, 1 \mathrm{~h}\right)$ human serum (HHS/199; Witt et al., 1976). Such suspensions of gonococci in $4 \mathrm{ml}$ volumes were killed by heating $\left(60^{\circ} \mathrm{C}\right.$ water bath, $1 \mathrm{~h}$ ) or by UV irradiation $\left(2 \mathrm{~cm}\right.$ from source for $1 \mathrm{~h}$, using a bactericidal lamp producing $8 \times 10^{4} \mathrm{~W} \mathrm{~cm}^{-2}$ at $30 \mathrm{~cm}$ from source with $90 \%$ of radiation in region of $253 \mathrm{~nm}$; Germicidal G15T8, Sylvania, U.S.A.). Exposure to the UV irradiation did not increase the temperature of the gonococcal suspensions. Control suspensions of gonococci were incubated at $37^{\circ} \mathrm{C}$ for $1 \mathrm{~h}$. In each case incubation was continued for a further $1 \mathrm{~h}$ with or without the addition of heat inactivated $\left(56^{\circ} \mathrm{C}, 1 \mathrm{~h}\right.$ ) rabbit antiserum raised against whole BS4 (agar) organisms $\left(32 \mu \mathrm{g} \mathrm{ml}^{-1}\right)$ (Veale $e$ t al., 1978) prior to centrifugation $(2000 \mathrm{~g}, 5 \mathrm{~min})$. Supernatants were discarded and deposited cells were resuspended in $4 \mathrm{ml}$ HHS/199. The viability of gonococci was assessed using a Thoma Chamber (Weber Scientific Instruments) after all treatments and was expressed as the percentage of the total number of organisms which formed colonies when plated on solid mediudm (Witt et al., 1976).

Phagocytosis test. Gonococcal suspensions, pretreated as described, were diluted to contain $1 \times 10^{8}, 5 \times 10^{8}$ or $1 \times 10^{9}$ organisms $\mathrm{ml}^{-1}$ and were mixed with equal volumes $(0.5 \mathrm{ml})$ of PMN phagocytes from human peripheral

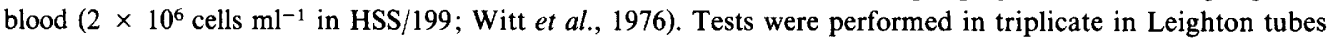
containing glass coverslips $(9 \times 35 \mathrm{~mm}$; covering $80 \%$ of the flat portion of the tube); tubes were agitated to ensure mixing and were incubated $\left(37^{\circ} \mathrm{C}, 1 \mathrm{~h}\right)$ to promote ingestion of gonococci by PMN phagocytes. Supernatants were removed after incubation and phagocytes that adhered as a deposit on the coverslips were washed three times with $5 \mathrm{ml}$ amounts of medium 199; these cells consisted mainly (about $80 \%$ ) of PMN phagocytes. Most of the remaining cells were mononuclear phagocytes which showed little phagocytic activity in the presence of gonococci and were not included in the results.

Coverslip preparations were fixed, Giemsa stained (Witt et al., 1976) and mounted in XAM (BDH) on a glass microscope slide. In some experiments, $10 \mu \mathrm{l}$ supernatant fluid was spread as evenly as possible over an area (approx. $10 \times 35 \mathrm{~mm}$ ) marked on a microscope slide and smears were fixed, Giemsa stained and mounted; the area of the smear was estimated using a microscope with vernier scales on the mechanical stage.

Assessment of cytotoxicity. Stained deposits of adherent PMN phagocytes were examined with a light microscope ( $\times 40$ objective lens, $\times 10$ eyepiece lens; area of field of view $0.126 \mathrm{~mm}^{2}$; Carl Zeiss) to assess percentage lysis. Lysed cells exhibited disruption of the cell membrane with partial extrusion of the cytoplasm and/or disintegration of the nuclear material. Sometimes complete disintegration of PMN phagocytes was observed leaving only cell debris, associated gonococci and remnants of nuclear material. Twenty fields of view (total area $2.52 \mathrm{~mm}^{2}$ ) in a pattern of four parallel rows of five fields of view over the cell deposit were examined. To overcome the subjective element of this estimation, all cell deposits were numbered randomly after fixation and the cytotoxicity was assessed before the identity of the slide was revealed. The numbers of lysed PMN phagocytes and the total (lysed and apparently intact) cells adhering as a deposit were estimated from the mean of three coverslip counts as detailed above. The numbers of lysed PMN phagocytes were quoted as a percentage of the total PMN phagocytes (see Table 1).

Smears prepared from supernatants were examined in the same way, with the exception that, as the distribution of cells throughout the smears was not normally uniform, counts were made on 40 fields of view; 10 were selected at regular intervals along the two longest edges of the smear and 20 fields at random in the body of the smear (total area $5 \cdot 04 \mathrm{~mm}^{2}$ ).

Assessment of phagocytic indices. The numbers of gonococci associated with 50 or 200 adherent PMN phagocytes in coverslip preparations in each of three stained cell deposits were counted after cytotoxicity had been assessed and the phagocytic index was calculated as the mean number of gonococci per infected PMN phagocyte.

\section{RESULTS}

\section{Cytotoxicity of gonococci [strain BS4 (agar)] for human peripheral blood PMN phagocytes}

The percentage lysis of PMN phagocytes exposed to gonococci pretreated in various ways is shown in Table 1 . The nominal percentage viability of gonococci in the untreated suspensions used in these experiments ranged from 67 to $>100$. Viable gonococci were toxic for PMN phagocytes and lysis increased as the ratio of viable organisms to phagocytes was raised from $50: 1$ to $250: 1$ and $500: 1$. Gonococcal suspensions heated at $60^{\circ} \mathrm{C}$ or exposed to UV irradiation 
Table 1. Percentage lysis and total numbers of adherent PMN phagocytes after incubation with gonococcal strain BS4 (agar)

Gonococci and phagocytes were mixed in the stated ratios and incubated for $1 \mathrm{~h}\left(37^{\circ} \mathrm{C}\right)$. Counts were made on the phagocyte deposit (about $80 \%$ PMN phagocytes). Figures not in parentheses represent the mean percentage lysis of adherent PMN phagocytes in 20 fields of view on each of three cell deposits; figures in parentheses represent the mean total of PMN phagocytes (lysed and intact) on each of three cell deposits $\left(\times 10^{-4}\right)$. Similar results were obtained in three further experiments.

\begin{tabular}{|c|c|c|c|c|c|c|c|}
\hline \multirow{4}{*}{$\begin{array}{l}\text { Expt and } \\
\text { blood donor }\end{array}$} & \multirow{4}{*}{$\begin{array}{c}\text { Gonococci : PMN } \\
\text { phagocyte ratio }\end{array}$} & \multicolumn{6}{|c|}{ Percentage lysis (and $10^{-4} \times$ total count) of PMNs } \\
\hline & & \multicolumn{6}{|c|}{ Gonococcal pretreatment*: } \\
\hline & & \multicolumn{3}{|c|}{ No antiserum } & \multicolumn{3}{|c|}{ Antiserum } \\
\hline & & Not killed & Heat killed & UV killed & Not killed & Heat killed & UV killed \\
\hline $1(\mathrm{HL})$ & $50: 1$ & $1(8 \cdot 3)$ & $1(6 \cdot 6)$ & $2(4 \cdot 0)$ & $3(12 \cdot 7)$ & $1(8 \cdot 0)$ & $1(9 \cdot 0)$ \\
\hline & $250: 1$ & $12(3 \cdot 7)$ & $1(5 \cdot 3)$ & $3(6 \cdot 8)$ & $16(2 \cdot 0)$ & $1(6 \cdot 3)$ & $1(13 \cdot 8)$ \\
\hline & $500: 1$ & $19(2 \cdot 0)$ & $1(3 \cdot 9)$ & $1(4.9)$ & $44(0 \cdot 9)$ & $7(1 \cdot 3)$ & $1(4 \cdot 6)$ \\
\hline $2(\mathrm{SC})$ & $50: 1$ & $7(6 \cdot 7)$ & $4(3 \cdot 0)$ & $12(3 \cdot 5)$ & $12(7 \cdot 0)$ & $2(6 \cdot 4)$ & $2(7 \cdot 1)$ \\
\hline & $250: 1$ & $12(4 \cdot 4)$ & $4(4 \cdot 2)$ & $3(4.9)$ & $20(1.7)$ & $4(2.9)$ & $3(2 \cdot 8)$ \\
\hline & $500: 1$ & $37(1 \cdot 2)$ & $2(4 \cdot 6)$ & $2(3 \cdot 9)$ & $59(1 \cdot 0)$ & $8(0 \cdot 7)$ & $2(6 \cdot 8)$ \\
\hline 3 (DR) & $50: 1$ & $3(5 \cdot 9)$ & $2(3 \cdot 8)$ & $2(5 \cdot 5)$ & $6(6 \cdot 7)$ & $1(7 \cdot 3)$ & $2(8 \cdot 5)$ \\
\hline & $250: 1$ & $8(5 \cdot 8)$ & $2(4 \cdot 4)$ & $4(3.4)$ & $13(3 \cdot 5)$ & $4(4 \cdot 0)$ & $2(8 \cdot 4)$ \\
\hline & $500: 1$ & $19(2 \cdot 9)$ & $1(2 \cdot 8)$ & $7(2.9)$ & $58(0 \cdot 5)$ & $5(1 \cdot 1)$ & $6(3.9)$ \\
\hline $4(\mathrm{PM})$ & $50: 1$ & $14(6 \cdot 6)$ & $4(3 \cdot 0)$ & $6(4-7)$ & $5(4 \cdot 5)$ & $4(5 \cdot 6)$ & $3(7 \cdot 4)$ \\
\hline & $250: 1$ & $19(3.5)$ & $6(3.4)$ & $11(3 \cdot 0)$ & $41(0.9)$ & $4(3 \cdot 2)$ & $7(3 \cdot 7)$ \\
\hline & $500: 1$ & $33(1 \cdot 3)$ & $11(4-4)$ & $12(3.7)$ & $65(0 \cdot 4)$ & $12(2 \cdot 3)$ & $8(1.4)$ \\
\hline
\end{tabular}

* Gonococcal pretreatment: suspensions that were not killed were incubated at $37^{\circ} \mathrm{C}$ for $1 \mathrm{~h}$; heat-killed suspensions were incubated at $60^{\circ} \mathrm{C}$ for $1 \mathrm{~h}$; UV-treated suspensions were irradiated for $1 \mathrm{~h}$ (see Methods). All suspensions were incubated for a further $1 \mathrm{~h}\left(37^{\circ} \mathrm{C}\right)$ with or without anti-gonococcal antiserum (see Methods).

\section{Table 2. Phagocytic indices of adherent PMN phagocytes after incubation with gonococcal strain BS4 (agar)}

The experiments are the same as those quoted in Table 1. Gonococci and phagocytes were mixed in the stated ratios and incubated for $1 \mathrm{~h}\left(37^{\circ} \mathrm{C}\right.$ ). Counts were made on the phagocyte deposit (about $80 \%$ PMN phagocytes): figures not in parentheses represent the mean phagocytic indices of approximately 600 (experiments 1-3) or 150 (experiment 4) intact adherent infected PMN phagocytes, figures in parentheses represent the mean percentage of lysed gonococci in 20 fields of view in each of three cell deposits.

Phagocytic index and percentage lysis of PMNs

\begin{tabular}{|c|c|c|c|c|c|c|c|}
\hline \multirow{3}{*}{$\begin{array}{l}\text { Expt and } \\
\text { blood donor }\end{array}$} & \multirow{3}{*}{$\begin{array}{c}\text { Gonococci : PMN } \\
\text { phagocyte ratio }\end{array}$} & \multicolumn{6}{|c|}{ Gonococcal pretreatment: } \\
\hline & & \multicolumn{3}{|c|}{ No antiserum } & \multicolumn{3}{|c|}{$\overbrace{}^{\text {Antiserum }}$} \\
\hline & & Not killed & Heat killed & UV killed & Not killed & Heat killed & UV killed \\
\hline $1(\mathrm{HL})$ & $\begin{aligned} 50 & : 1 \\
250 & : 1 \\
500 & : 1\end{aligned}$ & $\begin{array}{l}14(1) \\
19(12) \\
42(19)\end{array}$ & $\begin{array}{r}8(1) \\
14(1) \\
18(1)\end{array}$ & $\begin{array}{r}8(2) \\
15(3) \\
18(1)\end{array}$ & $\begin{array}{l}15(3) \\
25(16) \\
42(44)\end{array}$ & $\begin{array}{l}14(1) \\
20(1) \\
26(7)\end{array}$ & $\begin{array}{l}11(1) \\
17(1) \\
30(1)\end{array}$ \\
\hline $2(\mathrm{SC})$ & $\begin{array}{r}50: 1 \\
250: 1 \\
500: 1\end{array}$ & $\begin{array}{l}11(7) \\
13(12) \\
17(37)\end{array}$ & $\begin{array}{r}8(4) \\
9(4) \\
10(2)\end{array}$ & $\begin{array}{l}5(12) \\
7(3) \\
8(2)\end{array}$ & $\begin{array}{l}11(12) \\
15(20) \\
20(59)\end{array}$ & $\begin{array}{l}11(2) \\
12(4) \\
18(8)\end{array}$ & $\begin{array}{l}10(2) \\
12(3) \\
10(2)\end{array}$ \\
\hline $3(\mathrm{DR})$ & $\begin{array}{r}50: 1 \\
250: 1 \\
500: 1\end{array}$ & $\begin{array}{c}7(3) \\
10(8) \\
18(19)\end{array}$ & $\begin{array}{r}5(2) \\
8(2) \\
10(1)\end{array}$ & $\begin{array}{l}4(2) \\
7(4) \\
9(7)\end{array}$ & $\begin{array}{c}9(6) \\
12(13) \\
20(58)\end{array}$ & $\begin{array}{l}10(1) \\
13(4) \\
14(5)\end{array}$ & $\begin{array}{r}6(2) \\
7(2) \\
10(6)\end{array}$ \\
\hline $4(\mathrm{PM})$ & $\begin{array}{r}50: 1 \\
250: 1 \\
500: 1\end{array}$ & $\begin{array}{r}8(14) \\
17(19) \\
22(33)\end{array}$ & $\begin{array}{c}6(4) \\
12(6) \\
20(11)\end{array}$ & $\begin{array}{c}6(6) \\
10(11) \\
13(12)\end{array}$ & $\begin{array}{l}13(5) \\
20(41) \\
38(65)\end{array}$ & $\begin{array}{l}14(4) \\
17(4) \\
27(12)\end{array}$ & $\begin{array}{r}7(3) \\
14(7) \\
20(8)\end{array}$ \\
\hline
\end{tabular}


Table 3. Perecentage lysis of PMN phagocytes in suspension after incubation with gonococcal strain BS4 (agar)

\begin{abstract}
Gonococci and phagocytes were mixed in the stated ratios and incubated for $1 \mathrm{~h}\left(37^{\circ} \mathrm{C}\right)$. Counts were made on the phagocytes in suspension and represent the mean percentage lysis in 40 fields of view on each of three smears of supernatant phagocytes.
\end{abstract}

\begin{tabular}{|c|c|c|c|c|c|}
\hline \multirow[b]{4}{*}{ Expt no. } & \multirow{4}{*}{$\begin{array}{c}\text { Gonococci : PMN } \\
\text { phagocyte ratio }\end{array}$} & \multicolumn{4}{|c|}{ Percentage lysis of PMNs } \\
\hline & & \multicolumn{4}{|c|}{ Gonococcal pretreatment*: } \\
\hline & & \multicolumn{2}{|c|}{ No antiserum } & \multicolumn{2}{|c|}{ Antiserum } \\
\hline & & Not killed & Heat killed & Not killed & Heat killed \\
\hline 5 & $50: 1$ & 19 & 8 & 14 & 4 \\
\hline & $250: 1$ & 23 & 12 & 42 & 5 \\
\hline & $500: 1$ & 30 & 2 & 55 & 4 \\
\hline 6 & $50: 1$ & 15 & 6 & 43 & 9 \\
\hline & $250: 1$ & 41 & 15 & 41 & 8 \\
\hline & $500: 1$ & 61 & 8 & 37 & 6 \\
\hline 7 & $50: 1$ & 13 & 3 & 16 & 6 \\
\hline & $250: 1$ & 36 & 28 & 64 & 11 \\
\hline & $500: 1$ & 59 & 21 & 65 & 11 \\
\hline
\end{tabular}

contained no viable organisms as indicated by the inability to isolate c.f.u. from the treated suspensions. Little or no lysis was produced by the killed gonococci. Viable gonococci pretreated with antisera induced a greater percentage lysis than that produced by untreated viable organisms. In such experiments antiserum treated gonococci retained $47-78 \%$ viability. However, pretreatment of killed gonococci with antiserum had little or no effect on the cytotoxicity.

Changes were also observed in the total number of PMN phagocytes that adhered to coverslips (see figures in parentheses, Table 1). With untreated or antiserum treated live gonococci, a substantial decrease in the number of adherent cells accompanied the increases in percentage lysis. By contrast numbers of adherent cells did not decrease when suspensions were incubated with killed organisms except in the case of gonococci which had been heat killed and treated with antiserum. Here the total number of adherent PMN phagocytes was reduced without a concomitant increase in percentage lysis.

Phagocytic indices were also estimated in order to determine whether the inability of killed gonococci to elicit cytotoxicity was caused by a lack of ingestion (Table 2). As expected the phagocytic index increased as the ratio of gonococci to PMN phagocytes was raised. Previous electron microscopic observations (Penn et al., 1977b) would indicate that the majority of cellassociated gonococci were intracellular. The phagocytic indices for viable gonococci were greater than those for killed organisms at comparable gonococci to phagocyte ratios (Table 2). Gonococci from viable suspensions stained dark purple or blue when intracellular, whereas ingested organisms from killed suspensions appeared faint purple or pink, were often a similar shade of colour to the phagocyte cytoplasm and could only be distinguished by their presence in a phagolysosome. Pretreatment of both viable and killed organisms with antiserum resulted in increased phagocytic indices. However, at comparable phagocytic indices, the cytotoxicity (figures in parentheses in Table 2) produced by viable gonococci was always considerably greater than that of killed organisms.

The cytotoxicity of gonococci for PMN phagocytes in supernatant suspensions was investigated in three separate experiments which are shown in Table 3. Though more variable than those for the adherent phagocytes, the results showed the same essential pattern. Lysis of supernatant PMN phagocytes exposed to viable gonococci increased with increasing ratios of gonococci to PMN phagocytes and was comparable to that observed in deposit phagocytes (Table 1). Incubation with antiserum enhanced the cytotoxicity of viable gonococci for 
supernatant phagocytes in most experiments but differences were less consistent than for cells in the deposit. The lysis of supernatant phagocytes incubated with heat killed gonococci was generally greater than that in corresponding experiments with adherent PMNs but was low compared to the lysis induced by live organisms and did not increase greatly or consistently with increasing ratios of gonococci to phagocytes. Incubation of heat killed gonococci with antiserum did not enhance lysis. Lysis of phagocytes in the deposit was also measured in these experiments and the results showed a pattern and degree of lysis similar to those in the experiments of Table 1.

\section{DISCUSSION}

Viable gonococci had a toxic effect on PMN phagocytes as assessed by the increase in the percentage of lysed phagocytes adhering as a deposit to glass and also in the supernatant suspensions. This was accompanied by a decrease in the total number of cells adhering as a deposit. Cytotoxicity increased as the ratio of gonococci to phagocytes was raised.

Only viable gonococci were significantly cytotoxic and analysis of results for percentage lysis and phagocytic index indicated that the failure of killed gonococci to produce cytotoxicity was not due to differences in ingestion between killed and viable organisms. The apparently lower phagocytic indices at the same gonococci to PMN phagocyte ratios might have been due to reduced uptake of killed gonococci or to failure to detect ingested bacteria. These results indicate that gonococcal LPS per se was probably not directly responsible for the cytotoxicity as it should not have been denatured by the procedures used to kill gonococci.

Pretreatment of gonococci with antiserum increased the cytotoxic effect produced by viable organisms. It is unlikely, therefore, that the gonococcal factor or factors mediating the cytotoxic effect are the same as those which facilitate intracellular survival in PMN phagocytes as pretreatment of organisms with antiserum would also have neutralized their ability to survive intracellularly (Veale et al., 1979; Parsons et al., 1981). Possibly antiserum potentiated the destruction of the organisms and enhanced the release of the factor or factors responsible for cytotoxicity.

The type of damage observed in peripheral blood phagocytes reported in this present study resembles that seen in urethral pus (Novotny et al., 1977) where some phagocytes contain large numbers of gonococci (Veale et al., 1979). Such interactions between gonococci and PMN phagocytes may represent a mechanism whereby organisms that have survived intracellularly in phagocytes can be released and infect other cells. Indeed, in previous work (Casey et al., 1980) on the in vitro assessment of intracellular survival of gonococci in phagocytes of urethral exudate, lysis of infected phagocytes was sometimes seen (S. G. Casey, unpublished observations). Such a process would be of obvious importance in the pathogenesis of gonorrhoea.

We should like to thank the MRC for providing financial support, Mrs J. Lichfield for her excellent technical assistance and our blood donors.

\section{REFERENCES}

Casey, S. G., Veale, D. R. \& Smith, H. (1979). Demonstration of intracellular growth of gonococci in human phagocytes using spectinomycin to kill extracellular organisms. Journal of General Microbiology 113, 395-398.

Casey, S. G., Veale, D. R. \& Smith, H. (1980). Intracellular survival of Neisseria gonorrhoeae in human urethral exudate. FEMS Microbiology Letters 8, 97-100

Cheng, A., Kwapinski, J. B. G. \& Ronald, A. R. (1974). Isolation and immunological characterization of a unique toxic cytoplasmic polymer of type 1
Neisseria gonorrhoeae. Canadian Journal of Microbiology 20, 1163-1167.

GiBBS, D. L. \& ROBERTS, B. R. (1975). The interaction in vitro between human polymorphonuclear leukocytes and Neisseria gonorrhoeae cultivated in the chick embryo. Journal of Experimental Medicine 141, 155-171.

GregG, C. R., Melly, M. A., Hellerqvist, C. G., Coniglio, J. G. \& McGee, Z. A. (1981). Toxic activity of purified lipopolysaccharide of Neisseria gonorrhoeae for human fallopian tube mucosa. Journal of Infectious Diseases 143, 432-439. 
MÅrdh, P.-A., BaldetorP, B., HÅkansson, C. H., Fritz, H. \& Westrom, L. (1979). Studies of ciliated epithelia of the human genital tract 3 : mucociliary wave activity in organ cultures of human fallopian tubes challenged with Neisseria gonorrhoeae and gonococcal endotoxin. British Journal of Venereal Diseases 55, 256-264.

McGee, Z. A., Johnson, A. P. \& TAylor-Robinson, D. (1981). Pathogenic mechanisms of Neisseria gonorrhoeae: observations on damage to human fallopian tubes in organ culture by gonococci of colony type 1 or type 4 . Journal of Infectious Diseases 143, 413-422.

Melly, M. A., GregG, C. R. \& McGee, Z. A. (1981). Studies of toxicity of Neisseria gonorrhoeae for human fallopian tube mucosa. Journal of Infectious Diseases 143, 423-431.

Novotny, P., Short, J. A., Hughes, M., Miler, J. J., SyretT, C., Turner, W. H., Harris, J . R. W. \& Maclennan, I. P. B. (1977). Studies on the mechanism of pathogenicity of Neisseria gonorrhoeae. Journal of Medical Microbiology 10, 347368 .

Ovcinnikov, N. M. \& DelektorskiJ, V. V. (1971). Electron microscope studies of gonococci in the urethral secretions of patients with gonorrhoea. British Journal of Venereal Diseases 47, 419-439.

Parsons, N. J., KwaAsi, A. A. A., Turner, J. A., Veale, D. R., Perera, V. Y., Penn, C. W. \& Smith, H. (1981). Investigation of the determinants of the survival of Neisseria gonorrhoeae within human polymorphonuclear phagocytes. Journal of General Microbiology 127, 103-112.

Peacock, W. L. \& Schmale, J. D. (1969). Toxic constituents of Neisseria gonorrhoeae. Nature, London 221, 760-761.

Penn, C. W., Sen, D., Veale, D. R., Parsons, N. J. \& SMith, H. (1976). Morphological, biological and antigenic properties of Neisseria gonorrhoeae adapt- ed to growth in guinea-pig subcutaneous chambers. Journal of General Microbiology 97, 35-43.

Penn, C. W., Parsons, N. J., Sen, D., Veale, D. R. \& SMITH, H. (1977a). Immunization of guinea-pigs with Neisseria gonorrhoeae: strain specificity and mechanisms of immunity. Journal of General Microbiology 100, 159-166.

Penn, C. W., Veale, D. R. \& Smith, H. (1977b). Selection from gonococci grown in vitro of a colony type with some virulence properties of organisms adapted in vivo. Journal of General Microbiology 100, 147-158.

SCHERP, H. W. (1955). Neisseria and neisserial infections. Annual Review of Microbiology 9, 319-334.

SENFF, L. M., Wegener, W. S., Brooks, G. F., FinNerty, W. R. \& Makula, R. A. (1976). Phospholipid composition and phospholipase A activity of Neisseria gonorrhoeae. Journal of Bacteriology 127, 874-880.

Veale, D. R., Finch, H., Smith, H. \& Witt, K. (1976). Penetration of penicillin into human phagocytes containing Neisseria gonorrhoeae: intracellular survival and growth at optimum concentrations of antibiotic. Journal of General Microbiology 95, 353363.

Veale, D. R., Penn, C. W., Sutton, S. \& Smith, H. (1978). The effect of specific antiserum on the resistance of Neisseria gonorrhoeae to intracellular killing by phagocytes of human blood. Journal of General Microbiology 106, 129-136.

Veale, D. R., Goldner, M., Penn, C. W., Ward, J. \& SMITH, H. (1979). The intracellular survival and growth of gonococci in human phagocytes. Journal of General Microbiology 113, 383-393.

Witt, K., Veale, D. R., Finch, H., Penn, C. W., Sen, D. \& SMITH, H. (1976). Resistance of Neisseria gonorrhoeae grown in vivo to ingestion and digestion by phagocytes of human blood. Journal of General Microbiology 96, 341-350. 